\title{
HUBUNGAN NILAI CBR LABORATORIUM DAN DCP PADA TANAH YANG DIPADATKAN PADA RUAS JALAN DESA SEMISIR KABUPATEN KOTABARU
}

\author{
Sylvina Permatasari \\ Prodi Teknik Sipil Politeknik Kotabaru \\ E-mail : sylvinapermata@gmail.com
}

\begin{abstract}
ABSTRAK
Cara uji Dynamic Cone Penetrometer (DCP) merupakan suatu prosedur yang cepat untuk melaksanakan evaluasi kekuatan tanah dasar dan lapis pondasi jalan dengan biaya yang relatif kecil. Perencanaan tebal lapisan perkerasan bawah dan lapisan perkerasan atas serta lapis permukaan terlebih dahulu harus di uji kepadatan tanahnya. Pada penelitian ini membahas hubungan nilai CBR laboratorium dan DCP pada tanah yang dipadatkan di ruas Jalan Desa Semisir Kabupaten Kotabaru yang merupakan jalan yang akan digunakan perusahaan agar akses jalan pelabuhan menjadi mudah dilalui sehingga dapat membantu perusahaan melalui akses jalan tersebut.

Perhitungan hasil analisa data baik di lapangan maupun di laboratorium, diperoleh titik penelitian yang memiliki nilai hampir sama sehingga penggunaan alat DCP untuk penentuan CBR tanah (CBR perkiraan awal) di lapangan di Ruas Jalan Desa Semisir Kabupaten Kotabaru dapat dipakai sebagai suatu data perencanaan konstruksi jalan tanpa harus melakukan pengujian CBR lebih lanjut di laboratorium. Untuk mendapatkan berapa nilai DCP, nilai CBR, CBR desain dan nilai daya dukung tanah pada ruas Jalan dimana hasil pengujian menunjukkan rata-rata nilai DCP adalah $18,13 \mathrm{~mm}$, sedangkan rata-rata nilai CBR adalah $13,35 \%$ dan desain nilai CBR adalah $24,78 \%$ dengan Daya Dukung Tanah adalah 7,74\%.

Kondisi di lapangan saat pengujian sudah layak untuk ditingkatkan perkerasan lapisan permukaan aspal karena memiliki standar kepadatan minimum 6\%. Hasil nilai CBR tersebut akan menjadi rekomendasi untuk penentuan tebal lapis perkerasan dan tebal lapis permukaan pada Jalan tersebut
\end{abstract}

Kata Kunci : Kepadatan Tanah, DCP, CBR Lapangan, CBR Laboratorium, Desa Semisir.

\section{PENDAHULUAN}

Ruas Jalan Desa Semisir yang terletak di Kecamatan Pulau Laut Tengah Kabupaten Kotabaru dimana ruas jalan ini merupakan jalan yang digunakan oleh perusahaan agar akses jalan pelabuhan menjadi mudah dilalui sehingga dapat membantu perusahaan melalui akses jalan tersebut. Dalam upaya untuk meningkatkan layanan aktivitas dan kelancaran pengangkutan maka ruas Jalan Desa Semisir perlu ditingkatkan. Kualitas prasarana jalan yang tidak memadai pada ruas jalan Desa Semisir sebagian besar sudah rusak dan tidak nyaman untuk dilalui. Kekuatan struktur suatu perkerasan jalan sangat bergantung pada daya dukung tanah dalam kepadatan maksimum. 
Bila perkerasan jalan tidak mempunyai kekuatan secukupnya maka jalan tersebut akan mengalami kerusakan. Jadi untuk menilai kekuatan dasar yang hendak dipakai untuk menentukan tebal lapisan perkerasan digunakanlah CBR (California Bearing Ratio). Ada berbagai metode untuk mengestimasi nilai CBR, misalnya dari soil grading ataupun dari data plastisitas tanah. Namun dilapangan beberapa kesulitan sering dihadapi terutama dalam wilayah pedalaman dengan keterbatasan transportasi dan penyediaan perangkat pengujian. Alternatif alat yang bisa digunakan adalah Penetrasi Kerucut Dinamis (Dynamic Cone Penetrometer) yaitu suatu alat yang dirancang untuk menguji kekuatan lapisan granular dan tanah dasar perkerasan jalan secara tepat. Cara uji ini merupakan suatu prosedur yang cepat untuk melaksanakan evaluasi kekuatan tanah dasar dan lapis pondasi jalan dengan biaya yang relatif kecil. DCP telah banyak digunakan dalam sepuluh tahun terakhir untuk memperoleh data CBR untuk perencanaan perkerasan jalan karena 68 kali lebih cepat daripada melakukan pengujian di laboratorium dengan waktu yang lama dan peralatan yang lengkap.

\section{TINJAUAN PUSTAKA}

Jalan merupakan sarana yang sangat penting bagi perkembangan suatu daerah dan Negara untuk itu keamanan, kenyamanan, dan kelayakan suatu jalan sangat penting. Dalam hal ini pemeliharaan dan peningkatan jalan merupakan suatu kegiatan yang mutlak untuk dilakukan. Fungsi CBR Desain sebagai acuan menentukan hasil daya dukung tanah sebagai pemadatan tanah dasar. Pada peningkatan jalan dengan grafik $90 \%$ sesuai penelitian refrensi terdahulu. CBR bertujuan agar jalan aman dan nyaman saat mengakses jalan yang baru ditingkatkan agar menunjang prasarana masyarat diruas jalan tersebut

\section{Hubungan (Korelasi) Nilai CBR-DCP}

CBR adalah perbandingan antara beban penetrasi suatu bahan terhadap bahan standar dengan kedalaman dan kecepatan penetrasi yang sama. Pengujian penetrasi dengan menusukkan benda ke dalam benda uji dengan cara ini dapat dinilai kekuatan tanah dasar atau bahan lain yang dipergunakan untuk membuat perkerasan.

Dari data, didapat nilai DCP yang diambil adalah jumlah rata-rata dari penetrasi per pukulan. Dari nilai DCP yang ada, dapat dicari nilai CBR yang ada. Semakin kecil nilai penetrasi DCP, maka makin besar nilai CBR yang tejadi dan sebaliknya semakin besar nilai penetrasi DCP maka makin kecil nilai CBR yang terjadi. Nilai korelasi yang terjadi didapat dari beberapa percobaan yang sudah dilakukan oleh beberapa peneliti.

Hubungan DCP dan CBR digambarkan pada rumus berikut :

$\log (C B R)=a+b \log (D C P)$

Dimana:

$\mathrm{DCP}=$ nilai $\mathrm{DCP}(\mathrm{mm} / \mathrm{blow})$.

$\mathrm{a}=$ nilai konstanta antara 2,44 $-2,60$

$\mathrm{b}=$ nilai konstanta antara $1,07-1,16$

Persamaan diatas, dapat digunakan untuk beberapa jenis tanah, diantaranya tanah granular, cohesive, aggregate base course, hingga piedmont residual soil.

\section{Perbedaan Metode CBR dan Sand Cone}

Nilai CBR didapatkan langsung di lapangan, sesuai dengan kondisi tanah dasar saat itu namun digunakan untuk perencanaan tebal lapisan perkerasan yang lapisan tanahnya dasarnya sudah tidak akan dipadatkan lagi. Pemeriksaan dilakukan dalam kondisi kadar air tanah tinggi (musim penghujan) atau dalam kondisi terburuk yang mungkin terjadi. Untuk mengontrol apakah kepadatan 
yang diperoleh sudah sesuai dengan yang diinginkan. Pemeriksaan untuk tujuan ini tidak umum digunakan, lebih sering menggunakan pemeriksaan yang lain dengan metode sand cone. Untuk mengetahui kepadatan dari berbagai jenis material yang akan digunakan, yang sering digunakan adalah metode sand cone. Sand cone adalah salah satu alat untuk menentukan kepadatan di tempat dari lapisan tanah atau perkerasan yang telah dipadatkan, hasilnya didapat setelah contoh material yang didapat di lapangan kemudian diolah di laboratorium.

\section{METODE PENELITIAN}

Penelitian CBR laboratorium dilakukan di laboratorium dengan tahapan yang dilakukan di laboratorium antara lain : persiapan tanah, analisis saringan, batas-batas konsistensi, pemadatan, dan uji CBR. Tanah yang berasal dari lokasi di kering udara agar kondisi tanah tidak terlalu basah dan 37 lias disaring. Pemadatan menggunakan modiikasi proctor dengan mold untuk CBR.

\section{Lokasi Penelitian}

Lokasi Penelitian dilakukan di Ruas Jalan Desa Semisir Kecamatan Pulau Laut Tengah Kabupaten Kotabaru dengan panjang jalan 200 meter.

\section{Kondisi Jalan}

Pada Jalan Desa Semisir Kecamatan Pulau Laut Tengah Kabupaten Kotabaru dimana kondisi jalan yang masih berupa perkerasan lapisan pondasi bawah (LPB), oleh karena itu dilakukan pengujian daya dukung tanah. Untuk mengetahui berapa persen $(\%)$ daya dukung tanah di daerah tersebut

\section{Data Penelitian}

Data yang dipakai adalah data primer yaitu data yang didapat langsung dari lapangan yaitu panjang station jalan dan nilai DCP setiap station. Selain itu, juga digunakan data sekunder untuk menghitung nilai CBR desain dengan menggunakan aplikasi pengolah data (Microsoft Excel).

\section{Analisis Data}

Untuk menganalisa nilai koefisien reaksi tanah dasar pada ruas Jalan Desa Semisir Pulau Laut Tengah Kotabaru dilakukan dengan langkah-langkah sebagai berikut:

1. Mencari nilai CBR lapangan dilakukan dengan cara membagi beberapa titik pengujian dengan menggunakan alat DCP.

2. Tiap titik pengujian yang telah didapat nilai CBR, dianalisa dengan 2 cara yaitu cara grafis dan analisis, sehingga daya dukung tanah dinyatakan dalam nilai CBR dengan satuan $(\%)$.

\section{Perhitungan CBR DESAIN}

Perhitungan CBR desain dengan cara analisis dan dengan cara grafis.

Cara Analisis yaitu

$$
\begin{aligned}
\mathrm{CBR}= & \mathrm{CBR}_{\text {rata-rata }}-\left(\mathrm{CBR}_{\text {maks }}-\right. \\
& \left.\mathrm{CBR}_{\min }\right) / \mathrm{R} \\
= & 13,35+(27,95-6,61) / 3,18 \\
= & 20,06 \%
\end{aligned}
$$

Dimana nilai $\mathrm{R}$ tergantung dari jumlah data yang terdapat dalam 1 segmen.

Secara grafis

Prosedurnya adalah sebagai berikut :

a. Tentukan nilai CBR terendah.

b. Tentukan berapa banyak nilai CBR yang sama atau lebih besar dari masing-masing nilai CBR dan kemudian disusun secara tabel mulai dari nilai CBR terkecil sampai yang terbesar.

c. Angka terbanyak diberi nilai $100 \%$, angka yang lain merupakan persentase dari $100 \%$.

d. Dibuat grafik hubungan antara harga CBR dan persentase.

e. Nilai CBR Desain.

Dari hasil pemeriksaan daya dukung tanah dasar sepanjang jalan dari STA 0 \pm 000 sampai dengan STA 0+200, 
diperoleh nilai-nilai CBR yaitu antara lain: $11,94,18,20,27,95,10,19,6,61$, 7,24, 24,78, 18,89, 11,27, 10,89, 15,94, $14,12, \quad 10,28, \quad 12,24,8,99$. Adapun perhitungan nilai CBR desain secara grafis dapat dilihat pada Tabel 1 berikut:

Tabel 1. Perhitungan Nilai CBR Desain secara

\begin{tabular}{|c|c|c|}
\hline CBR & $\begin{array}{c}\text { Jumlah yang } \\
\text { sama } \\
\text { atau lebih } \\
\text { besar }\end{array}$ & $\begin{array}{c}\text { Persen }(\% \\
\text { yang same } \\
\text { atau lebih } \\
\text { besar }\end{array}$ \\
\hline 27,95 & 15 & $\begin{array}{l}15 / 15 \times 100= \\
100 \%\end{array}$ \\
\hline 24,78 & 14 & $\begin{array}{l}14 / 15 \times 100= \\
93,3 \%\end{array}$ \\
\hline 18,89 & 13 & $\begin{array}{l}13 / 15 \times 100= \\
86,7 \%\end{array}$ \\
\hline 18,20 & 12 & $\begin{array}{l}12 / 15 \times 100= \\
80,0 \%\end{array}$ \\
\hline 14,12 & 11 & $\begin{array}{l}11 / 15 \times 100= \\
73,3 \%\end{array}$ \\
\hline 12,24 & 10 & $\begin{array}{l}10 / 15 \times 100= \\
66,7 \%\end{array}$ \\
\hline 11,94 & 9 & $\begin{array}{l}9 / 15 \times 100= \\
60,0 \%\end{array}$ \\
\hline 11,27 & 8 & $\begin{array}{l}8 / 15 \times 100= \\
53,3 \%\end{array}$ \\
\hline 10,89 & 7 & $\begin{array}{l}7 / 15 \times 100= \\
46,7 \%\end{array}$ \\
\hline 10,28 & 6 & $\begin{array}{l}6 / 15 \times 100= \\
40,0 \%\end{array}$ \\
\hline 10,19 & 5 & $\begin{array}{l}5 / 15 \times 100= \\
33,3 \%\end{array}$ \\
\hline 8,99 & 4 & $\begin{array}{l}4 / 15 \times 100= \\
26,7 \%\end{array}$ \\
\hline 7.24 & 3 & $\begin{array}{l}3 / 15 \times 100= \\
20,0 \%\end{array}$ \\
\hline 6,70 & 2 & $\begin{array}{l}2 / 15 \times 100= \\
13.3 \%\end{array}$ \\
\hline 6,61 & 1 & $\begin{array}{l}1 / 15 \times 100= \\
6.7 \%\end{array}$ \\
\hline
\end{tabular}

Dari Tabel 1, nilai CBR yang digunakan untuk desain tabel untuk perkerasan jalan yang digunakan adalah CBR pada kondisi 90\% adapun pada Grafik 1 adalah CBR desain $90 \%$ yaitu sebagai berikut :

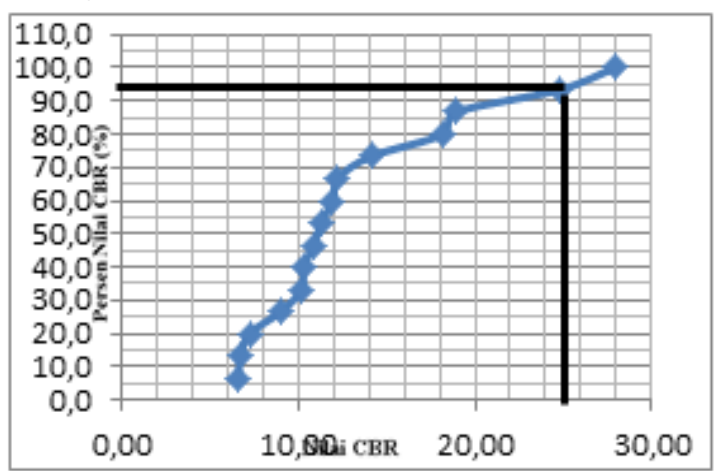

Grafik 1. Nilai CBR Desain 24,78\%

\section{Perhitungan Daya Dukung Tanah}

Pada perhitungan daya dukung tanah yang memuat data hasil CBR tanah dasar sebesar $24,78 \%$. Secara grafis maka akan didapat nilai daya dukung tanah dapat dilihat pada Grafik 2 berikut :
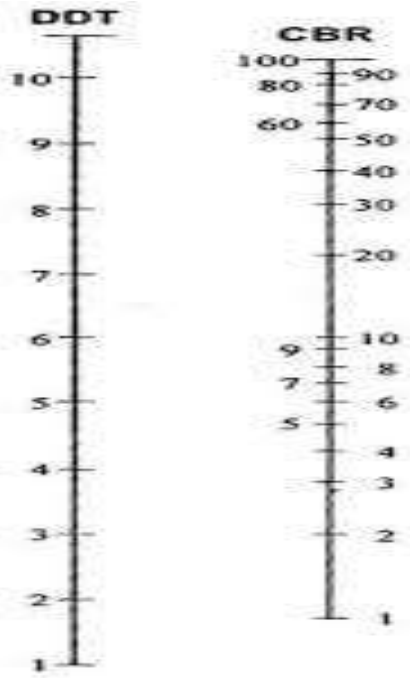

Grafik 2. Hubungan CBR dan DDT

Adapun perhitungan daya dukung tanah adalah sebagai berikut:

$D D T=1,6649+4,3592 \log (\mathrm{CBR}$ Desain)

$$
\begin{aligned}
& =1,6649+4,3592 \log (24,78) \\
& =7,74 \%
\end{aligned}
$$

\section{HASIL PENELITIAN}

\section{Hasil Penelitian di laboratorium}

Penelitian di laboratorium menjelaskan bahwa hasil perhitungan CBR yang diperoleh di laboratorium dengan dilapangan di Ruas Jalan Desa Semisir Kecamatan Pulau Laut Tengah terdapat sekitar $80 \%$ yang memiliki nilai yang hampir sama, sehingga penggunaan alat DCP untuk penentuan CBR tanah di lapangan dapat dipakai untuk suatu data perencanaan konstruksi jalan tanpa harus melakukan pengujian CBR lebih lanjut di laboratorium.

\section{Hasil Penelitian di Lapangan}

Pengujian sampel untuk kepadatan tanah di Jalan Desa Semisir Pulau Laut Tengah Kotabaru menggunakan alat DCP bertujuan agar menentukan kepadatan 
tanah layak atau belum peningkatan jalan, seperti ketentuan SNI 4153:1975 yaitu cara uji kepadatan tanah dengan alat DCP adalah menentukan hasil DDT yang diketahui pada pegujian minimum $6 \%$ tanah tersebut sudah layak ditingkatkan jalan.

Dari hasil data penelitian yang telah diuji setiap sampel di lapangan menunjukan kepadatan tanah di Jalan Desa Semisir Pulau Laut Tengah Kotabaru dapat diketahui yaitu sebagai berikut :

Tabel 2. Rekapitulasi hasil perhitungan kepadatan di lapangan

\begin{tabular}{lccr}
\hline No. & $\begin{array}{c}\text { Titik } \\
\text { Uji }\end{array}$ & $\begin{array}{c}\text { DCP } \\
\text { (mm/Tumbukan) }\end{array}$ & $\begin{array}{c}\text { CBR } \\
\mathbf{( \% )}\end{array}$ \\
\hline 1. & 1 & 17,17 & 11,94 \\
\hline 2. & 2 & 11,78 & 18,20 \\
\hline 3. & 3 & 8,04 & 27,95 \\
\hline 4. & 4 & 19,78 & 10,19 \\
\hline 5. & 5 & 29,10 & 6,1 \\
\hline 6. & 6 & 26,85 & 7,24 \\
\hline 7. & 7 & 8,95 & 24,78 \\
\hline 8. & 8 & 11,40 & 18,89 \\
\hline 9. & 9 & 18,08 & 11,27 \\
\hline 10. & 10 & 18,65 & 10,89 \\
\hline 11. & 11 & 28,78 & 6,70 \\
\hline 12. & 12 & 14,78 & 14,12 \\
\hline 13. & 13 & 19,63 & 10,28 \\
\hline 14. & 14 & 16,80 & 12,24 \\
\hline 15. & 15 & 22,12 & 8,99 \\
\hline \multicolumn{2}{c}{ Rata-rata } & $\mathbf{1 8 , 1 3}$ & $\mathbf{1 3 , 3 5}$ \\
\hline \multicolumn{5}{c}{}
\end{tabular}

Adapun hasil dari tabel 2 tersebut, dapat dilihat pada gambar Grafik 3 berikut :

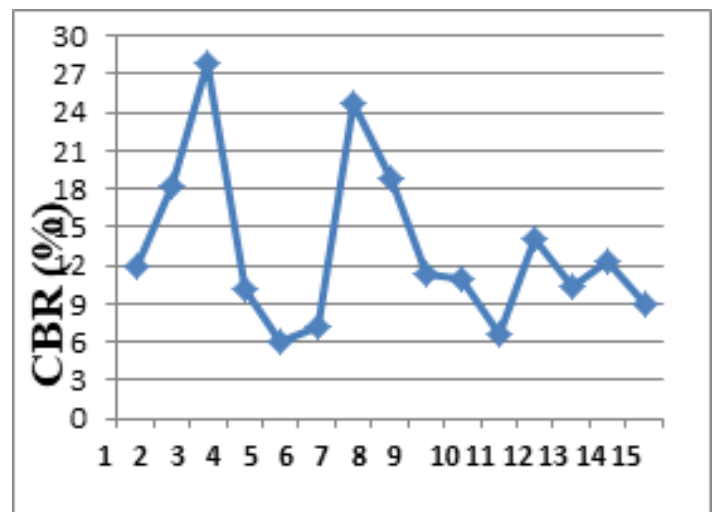

Grafik 3. Hasil perhitungan kepadatan di lapangan.

\section{KESIMPULAN}

Dari hasil penelitian kepadatan tanah pada Jalan Desa Semisir Pulau Laut Tengah Kotabaru menggunakan DCP dapat disimpulkan sebagai berikut:

1. Hasil pengujian menunjukkan ratarata nilai DCP adalah $18,13 \mathrm{~mm}$.

2. Rata-rata nilai CBR adalah $13,35 \%$. Nilai CBR tertinggi pada STA $0 \pm 000$ titik 3 sebesar $27,95 \%$ dan terendah pada STA 0 \pm 050 titik 5 sebesar 6,61\%. Desain nilai CBR adalah $24,78 \%$, dengan DDT adalah $7,74 \%$.

3. Kondisi di lapangan saat pengujian, sudah layak untuk ditingkatkan perkerasan lapisan permukaan atas, karena memenuhi standar kepadatan minimum $6 \%$.

4. Penelitian di laboratorium menjelaskan bahwa hasil perhitungan CBR yang diperoleh di laboratorium dengan dilapangan di Ruas Jalan Desa Semisir Kecamatan Pulau Laut Tengah terdapat sekitar $80 \%$ yang memiliki nilai yang hampir sama, sehingga penggunaan alat DCP untuk penentuan CBR tanah di lapangan dapat dipakai untuk suatu data perencanaan konstruksi jalan tanpa harus melakukan pengujian CBR lebih lanjut di laboratorium.

\section{DAFTAR PUSTAKA}

A, S., Kolase, P. K., Desai, S. P., \& Desai, A. K. (2015). Study of the Light Weight Deflectometer and Reviews. Study of the Light Weight Deflectometer and Reviews, 3(6), 42-46.

Bowles J.E., 1991. Sifat-sifat Fisis dan Geoteknis, Jilid I Edisi ke 4.

Burhanuddin, \& Junaidi. (2018). Hubungan Empiris Daya Dukung Tanah Dasar Menggunakan Alat Dynamic Cone Penetrometer (DCP) Dan California Bearing Ratio (CBR) Rendaman Untuk 
Disan Perkerasan Lentur Jalan Raya. Jurnal Teknik Sipil Universitas Syiah Kuala, 1, 553558.

Burnham T. R., 1997. Application of the Dynamic Cone Penetrometer to Minnessota Department of Transportation Pavement Assesssment Procedures, Report No. MN/RD - 97/19

Civil Engineering Dept. U. K, Correlation of CBR \& Dynamic Cone Penetrometer Strength Measurement of Soil, Jurnal November 1985.

Das B.M..1994, Mekanika Tanah I dan II. Penerbit Erlangga

NCDOT-Geotechnical Engineering Unit, Dynamic Cone Penetrometer Testing for Subgrade Stability, September 2005 http://www.ncdot.org/

Farshad Amini, 2003. Potential Applications of Dynamic and Static Cone Penetrometers in MDOT Pavement Design and Construction. Department of Civil Engineering, Jackson State University September 2003

Harison J., 2005. Testing and Data Collection Illinois Department of Transportation PTA-T4, Beuro of Materials and Physical Research

Jackson State University, Potential Application of Dynamic and Static Cone Penetrometers in MDOT Pavement Design and Construction, Jurnal September 2003

Jauhari, Zulfikar, 2011, Manajemen Pelaksanaan Jalan Tol MojokertoKertosono STA O+000 sampai STA 0+350 Menggunakan Perkerasan Kaku Kabupaten Mojokerto Jawa Timur. Fakultas Teknik Sipil Dan Perencanaan Institut Teknologi Sepuluh Nopember Surabaya.

Joel, Julio, 2016. Menerapkan Pengujian DCP Sebagai Solusi Untuk
Mendapatkan Nilai Cbr Lapangan Pada Proyek Pelebaran Ruas Jalan TumpaanLopana Di Kab. Minahasa Selatan. Politeknik Negeri Manado : Jurusan Teknik Sipil, Manado.

Jones C.R. and J. Rolt, 1991. Operating Instructions for the TRL Dynamic Cone Penetrometer (2nd Edition). Transport Research Laboratory

Masykur, M., \& Kurniawan, S. (2017). Analisa Pengujian Dynamic Cone Penetrometer (DCP) Untuk Daya Dukung Tanah Pada Perkerasan Jalan Overlay (Studi Kasus: Ruas Jalan Metro-Tanjungkari STA 7+000 s/d STA 8+000). TAPAK (Teknologi Aplikasi Konstruksi): Jurnal Program Studi Teknik Sipil, 7(1), 52-63.

Peraturan Pemerintah Nomor 34 Tahun 2006

Rika, Sylviana, 2013. Pengukuran Nilai California Bearing Ratio (CBR) Lapis Perkerasan Aspal Dengan Alat Dynamic Cone Penetrometer $(D C P)$. Universitas Islam 45 Bekasi: Jurusan Teknik Sipil.

Saskactchewan Highways and Transpportation Standard Test Procedures Manual http://www.highways.gov.sk

SNI 03-4267, Pedoman Cara Uji CBR Dengan Dynamic Cone Penetrometer (DCP), Departemen Pekerjaan Umum 1999

Sukirman, Silvia. 1999. Perkerasan Lentur Jalan Raya. Nova, Bandung.

Syahruddin S, Arie, 2010. Pengujian Daya Dukung Perkerasan Jalan Dengan Dynamic Cone Penetrometer (DCP) Sebagai Standar Untuk Evaluasi Perkerasan Jalan. Politeknik Pasir Pengairan: Program Studi Teknik Sipil, Pasir Pengairan. 